\title{
Long-term microclimate study of a peatland in Central Europe to understand microrefugia
}

\author{
Sandra Słowińska ${ }^{1} \cdot$ Michał Słowiński $^{2} \cdot$ Katarzyna Marcisz $^{3} \cdot$ Mariusz Lamentowicz $^{3}$
}

Received: 10 January 2021 / Revised: 28 November 2021 / Accepted: 12 January 2022 / Published online: 3 February 2022

(c) The Author(s) 2022

\begin{abstract}
Peatlands perform many important ecosystem functions at both the local and global scale, including hydrologic and climatic regulation. Although peatlands often act as climatic microrefugia, they have rarely been the subject of long-term microclimatic studies. In this study, we aimed to compare the local climatic conditions of a mid-forest mire to that of an open area and examine the differences in microclimates within the mire based on plant community diversity, shading, and water table depths. The peatland studied in this work was significantly cooler than the reference site, mainly due to a higher decline in nighttime air temperatures. However, the daily maximum air temperature near the ground was often higher. We also noticed that microclimates significantly differed within the studied peatland. Wet and shaded microsites were cooler than the sites having a lower water level and receiving higher amounts of solar radiation. The results of the study suggest that peatlands have locally cooler climates, and thus can serve as climate change refugia. These findings can help us interpret reconstructed data from the peat archive, and, when combined with experiments, identify tipping points for peatland ecosystems.
\end{abstract}

Keywords Microclimate $\cdot$ Peatlands $\cdot$ Local climate $\cdot$ Climate change refugia $\cdot$ Air temperature $\cdot$ Vapor pressure deficit

\section{Introduction}

Peatlands, like any other ecosystem, are affected by climate change, which is expected to worsen in the coming decades (Malhi et al. 2020). Climate change causes a variety of disturbances in peatlands, ranging from hydrological to trophic changes, which are further exacerbated by detrimental human land-use practices. Although peatlands cover only $3 \%$ of the earth's surface, they serve as carbon sinks, water reservoirs, habitat for specific species, and natural paleoenvironmental archives (Amesbury et al. 2019; Jassey et al. 2018; Nichols and Peteet 2019). Undisturbed

Sandra Słowińska

s.slowinska@twarda.pan.pl

1 Climate Impacts Laboratory, Department of Geoecology and Climatology, Institute of Geography and Spatial Organization, Polish Academy of Sciences, Warsaw, Poland

2 Past Landscape Dynamics Laboratory, Institute of Geography and Spatial Organization, Polish Academy of Sciences, Warsaw, Poland

3 Climate Change Ecology Research Unit, Faculty of Geographical and Geological Sciences, Adam Mickiewicz University, Poznań, Poland peatlands (mires) act as net carbon sinks and contribute to global cooling if water inflow (precipitation, groundwater supply) exceeds water losses (evapotranspiration, runoff), and thus become the habitats of special management and protection (Limpens et al. 2008; Moore et al. 2002). Some ecosystems quickly show the effects of climate change than others (Bertrand et al. 2011; Settele et al. 2014; von Arx et al. 2012). Therefore, researchers have been performing intensive experimental studies on the response of peatland ecosystems to climate changes (Buttler et al. 2015; Delarue et al. 2011; Dieleman et al. 2015; Reczuga et al. 2020; Turetsky et al. 2011).

Despite often acting as microrefugia, as evidenced by the results of palaeoecological research, peatlands have rarely been the subject of long-term microclimatic studies (Dítě et al. 2018; Jones et al. 2009; Wieder 2006). Microrefugia are sites displaying favorable local conditions that allow species populations to survive beyond their main distributions during unfavorable regional climatic conditions (Dobrowski 2011). Morelli et al. (2016) defined climate change refugia as areas relatively buffered from contemporary climate change over time that enable persistence of valued physical, ecological, and socio-cultural resources, and highlighted their importance as a climate change adaptation tool. 
The existence of a given refugium may be determined by external factors, such as terrain location (terrain-mediated refugia) (Dobrowski 2011, Straberg et al. 2020) and water availability (hydrological refugia) (McLaughlin et al. 2017), as well as internal regulatory processes (ecosystemprotected refugia) (Shur and Jorgenson 2007; Waddington et al. 2015). Usually, several factors work together in synergy. According to paleoecological studies, some peatlands can resist disturbances and remain resilient for thousands of years (Lamentowicz et al. 2019a; Łuców et al. 2020).

Climate change forces living organisms to adapt to local climates or become extinct (Birks and Birks 2004; Huntington et al. 2020; Moore 2011); however, some species may survive in locations that are characterized by local favorable environmental conditions outside their main area of distribution. Such locations are referred to as microrefugia (Ashcroft and Gollan 2013; Gubler et al. 2018; Rull 2009). Numerous studies analyzing different temporal and spatial microhabitat characteristics have indicated that the heterogeneity of habitats (Gallé et al. 2019), including their microclimates (Bramer et al. 2018), is underestimated. Free-air measurements obtained in standard meteorological stations at a height of 1.5-2.0 m over short grass or natural soil, in accordance with the guidelines of the World Meteorological Organization (WMO) (De Frenne et al. 2019; WMO 2018), provide general data about the macroclimate of an ecosystem. However, these measurements are not representative of a majority of the ecosystems. Although daily, seasonal, and interannual variations as well as multiyear trends converge with free-air measurements, the values of meteorological factors may significantly vary. The range of values of biotic and abiotic environmental factors determines whether or not a species exists in a given location. Therefore, due to the lack of monitoring and analysis of habitat properties, including microclimate, much information about individual species and their environmental requirements is unknown. To avoid extinction, an increase in global air temperature and the resulting habitat changes force species to track or adapt to the modified regional climate (Wasof et al. 2013). In recent years, species distribution models have been developed to aid in this analysis. Nevertheless, these models require specific measurement data for improvement and validation (Lembrechts et al. 2019).

Differences in macro- and microclimate may be especially large in ecosystems with high shading (forests), diverse landscape topography (mountains, young glacial landscapes) (Dobrowski 2011), and high soil moisture (e.g., wetlands) (Ashcroft and Gollan 2013; De Frenne et al. 2013; Słowińska 2016; Zellweger et al. 2019). This is also the case with urban areas, in which the phenomenon of urban heat island (UHI) is often observed (Manoli et al. 2020; Oke 1987; Stanley et al. 2019). In contrast to microclimate of forests, microclimate of peatlands has not been widely studied thus far (Chen et al. 1993; De Frenne et al. 2019; von Arx et al. 2012; Zellweger et al. 2019). For instance, De Frenne et al. (2019) performed a global analysis of the thermal buffering capacity of forests and showed that the mean and maximum understory temperatures were, on average, $1.7 \pm 0.3{ }^{\circ} \mathrm{C}$ and $4.1 \pm 0.5^{\circ} \mathrm{C}$ cooler, respectively (mean \pm s.e.m.), while the minimum understory temperature was $1.1 \pm 0.2^{\circ} \mathrm{C}$ warmer compared to the macroclimate outside the forest. A significant amount of climatological studies have also been conducted in cities. UHI, a common phenomenon in which temperatures in urban areas are higher than in surrounding rural areas, can be distinguished by a several Kelvin degrees warmer air temperature than the rural areas. For example, in Warsaw (Poland), the yearly average UHI index in 2011-2012 was a little more than $2.0^{\circ} \mathrm{C}$ and the maximum index values were above $8.0^{\circ} \mathrm{C}$ (Kuchcik et al. 2014; Zhao et al. 2014).

Peatlands are ecosystems with diverse water and nutrient supply, ranging from oligotrophic bogs to extremely rich fens (Charman 2002; Hajek et al. 2006; Succow 1988). Due to their geology, microtopography, water level, and nutrient inflow, they are also heterogeneous within a given type. All these factors have a significant impact on the composition of vegetation in peatlands (Chronakova et al. 2019; Rydin and Jeglum 2013). Most peatlands are extremely sensitive to interannual changes in meteorological conditions because their functioning is dependent on the precipitation-to-evapotranspiration ratio (Baldocchi et al. 2018; Samson et al. 2018; Yu et al. 2011). Studies that have been conducted so far on microclimate of peatlands were short term or a part of other environmental analyses, such as those focusing on greenhouse gas fluxes (Juszczak et al. 2012; Kellner 2001) or plant and microbial composition (Robroek et al. 2014). Worrall et al. (2019) conducted one of the few studies that analyzed the thermal properties of the surface of a reclaimed peatland. The authors demonstrated that a lowland peatland with a high water level could act as a cool, humid island during daytime when the agricultural area was considered on a landscape scale. Liao et al. (2013) reported similar findings based on a comparison of the microclimatic edge effects between wetlands and farmlands in northeastern China.

The object of the present study is the Linje mire, a microrefugium. Dwarf birch (Betula nana), which is a glacial relict, has been documented in a peat core since the period of Younger Dryas around 12,000 years ago (Noryśkiewicz 2005). Considering the knowledge gap in the long-term research on peatland microclimate, in this study we aimed to (i) analyze the local climate features of the mid-forest Linje mire, as an example of this type of ecosystem, in comparison to an open site, and determine the seasonal climate differences between the mid-forest mire and the open site, and (ii) examine the differences in microclimates of the microsites on the mire selected based on the diversity of plant 
communities, shading, and depths of the water table. We chose the peatland with one of the longest climate records in Poland for this study.

\section{Materials and methods}

\section{Study site}

The site chosen for this study was the mid-forest Linje mire, located in northern Poland $\left(53^{\circ} 11,015^{\prime \prime} \mathrm{N}, 18^{\circ}\right.$ 18,034" E; Fig. 1). The mire is characterized by a temperate climate, which is influenced by both humid air masses from the Atlantic Ocean and dry inland masses. Its mean annual air temperature is $8.2{ }^{\circ} \mathrm{C}$, and precipitation was recorded at $528.4 \mathrm{~mm}$ during the years 1951-2015 (station index 12250 located about $25 \mathrm{~km}$ from the mire, data from the Institute of Meteorology and Water Management). The mire is a poor fen with ombrotrophic vegetation that covers approximately 6 ha. It is situated in a terrain depression between a moraine hill and a sandur with a dunes system which is reflected by its water conditions (Słowińska et al. 2010). The averaged terrain denivelation in the mire's direct catchment area reaches several meters.
The hydrochemistry of peatlands, and thus vegetation, is significantly influenced by their geological surroundings (Wheeler and Proctor 2000). The Linje mire was drained in the second half of the nineteenth century by allowing water from the mire to flow out to the south (Słowińska et al. 2010). Drainage was stopped later, and the peatland is currently protected, but drainage ditches can still be seen on the surface (Lamentowicz et al. 2016). This study analyzed the microclimatic features of five microsites consisting of different plant communities as follows: MS1: Phragmitetea and Scheuchzerio-Caricetea nigrae (lawn structure comprising herb and moss layers); MS2 and MS5: Sphagno squarrosi-Alnetum (hummock-hollow structure comprising moss, herb, and low shrub layers); MS3: Ledo-Sphagnetum magellanici (hummock-hollow structure comprising moss and low shrub layers); and MS4: Eriophorum vaginatum-Sphagnum fallax (hummock-hollow structure comprising moss, herb, and low shrub layers) (Matuszkiewicz 2001). The vegetation composition of each studied microsite is described in Fig. 1. Microsites MS2 and MS5 were located close to the edge of the mire, and were therefore additionally shaded by tall Salix cinerea (MS2), Betula pubescens (MS2), and Alnus glutinosa (MS2, MS5).

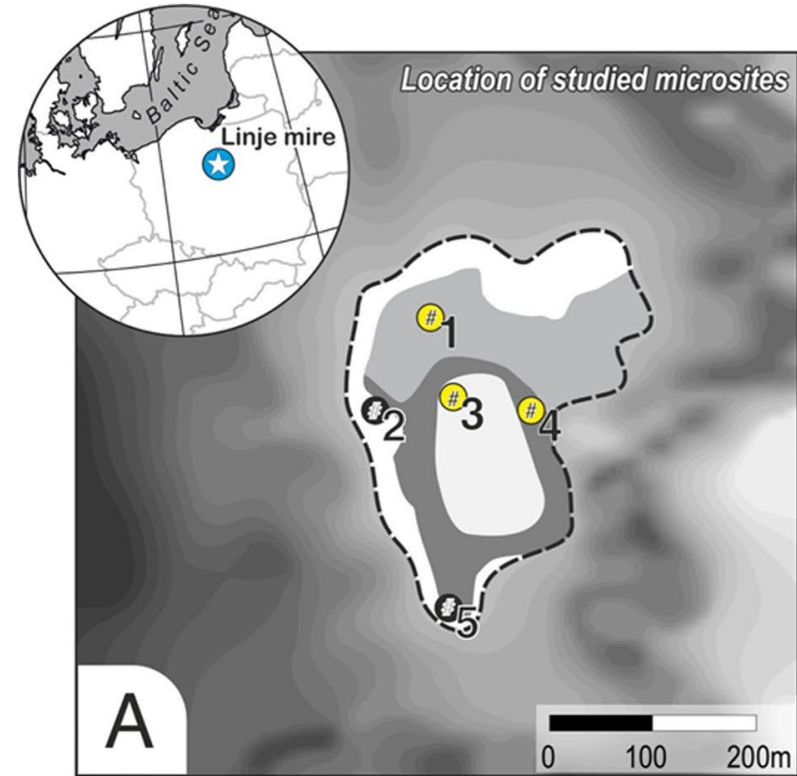

Vegetation patterns on Linje mire (Kloss and Kucharski 2005):

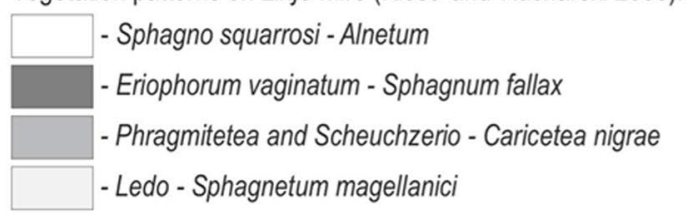

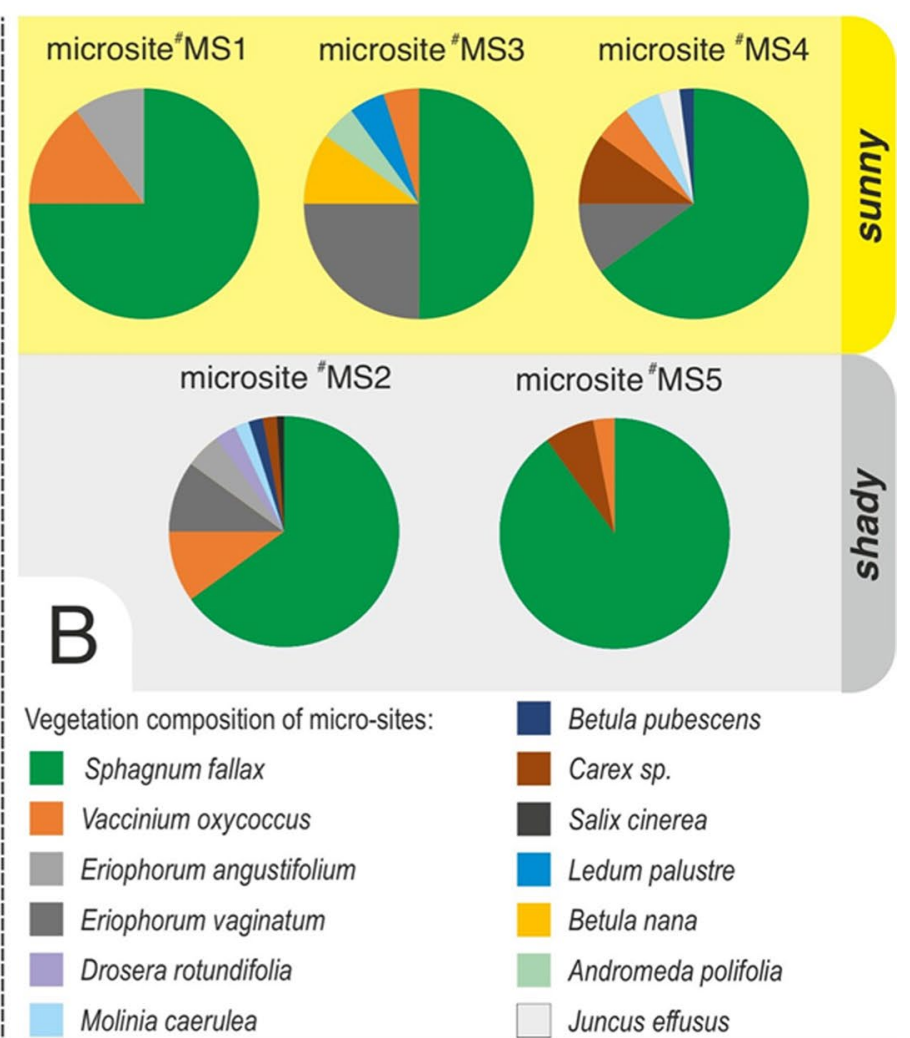

Fig. 1 A Location of the Linje mire and the studied microsites (MS1-MS5), and B the vegetation composition of each microsite 


\section{Field infrastructure and meteorological measurements}

In order to determine the local climate features of the mire, the air temperature and humidity were recorded in its middle part (next to MS3; Fig. 1), and in the open site (reference) located $650 \mathrm{~m}$ away from the mire in a nearby village. The open site was situated on a lawn within the premises of a local company (Supplementary Information, Fig. 1). Temperature and relative humidity data loggers (HOBO U23 Pro v2; Onset Computer Corporation, USA) were installed at a height of 30 and $150 \mathrm{~cm}$, and worked in 10-min intervals. The same measurements were taken at the reference site as well. Air temperature and humidity monitoring has been carried out in the mire and reference site from the year 2009, but for this study, we only considered the data for the period from April 2, 2012, to December 17, 2015, when all four data loggers (two at the mire and two at the reference site) were functioning correctly, and no statistical methods were needed to fill in data gaps.

As mentioned above, microclimatic studies were carried out in five microsites characterized by different plant communities and water conditions (Fig. 1). A data logger (EM-50; METER Group, USA), consisting of air temperature and humidity sensors placed in the radiation shield, photosynthetically active radiation (PAR) sensor, and leaf wetness (LW) sensor, was installed in each microsite. The air temperature, humidity, and PAR sensors were placed at a height of $30 \mathrm{~cm}$, while the LW sensor was placed right above the surface of mosses. Groundwater wells with HOBO Water Level Data Loggers (Onset Computer Corporation, USA) were installed next to each micrometeorological station. Meteorological parameters were recorded in 10-min intervals, and the data were collected from April 15 to November 9, 2012, with the exception of the period from June 14 to July 8 when the logger failed at one of the plots. The depths of the water table were measured at 1-h intervals, and the results were averaged for the same period as meteorological parameters.

\section{Statistical analysis of meteorological data}

The differences in the daily average, minimum and maximum temperatures, and vapor pressure deficit (VPD) between the mire and open (reference) site were used to determine the local climate features of the mire. VPD was calculated as the difference between the saturated and actual vapor pressure of air at each time step (10 min), and the results were averaged as other microclimatic variables (Allen et al. 1998). To determine the amount of heat in the ecosystem, growing degree days (GDD) with base $0^{\circ}$ were estimated as a sum of all positive daily averages in degree Celsius for every year and their average value was calculated. The days of ground frost were calculated as days when the minimum air temperature at the height of $30 \mathrm{~cm}$ dropped below $0{ }^{\circ} \mathrm{C}$ while a positive maximum temperature occurred on a given day.

The microclimatic conditions of each microsite were characterized by determining the following indicators related to air temperature $(T)$, relative humidity $(R H)$, and VPD: averaged daily mean $\left(T_{\text {mean }}, R H_{\text {mean }}, \mathrm{VPD}_{\text {mean }}\right)$, minimum $\left(T_{\min }, R H_{\min }, \mathrm{VPD}_{\min }\right)$ and maximum values $\left(T_{\max }, R H_{\max }\right.$, $\mathrm{VPD}_{\max }$ ), and absolute minimum and maximum values (only for temperature: $T_{\operatorname{minAbs}}, T_{\operatorname{maxAbs}}$ ). The diurnal temperature range (DTR) was calculated as the difference between the daily maximum and minimum values. The sum of PAR was calculated for the investigated period to compare the amount of solar energy reaching the ground at each microsite. GDD with base $0^{\circ}$ were calculated as described above. Data obtained from the LW sensors were used to estimate the sum of hours with the presence of free water resulting from dew, fog, or rainfall close to the surface of mosses. This information indicates the microsite where the surface of mosses was most often wet. The course of temperature and VPD in July 2012 was also analyzed, based on hourly averages, to identify the differences in microclimates between the studied microsites during extremely hot days. Data on water table depths (WTDs) were used to determine the water conditions at each microsite. The groundwater level was recorded at 1-h intervals, and the results were averaged to the daily value and then to the investigated period.

The distribution of the differences was illustrated in boxplot charts, and the significance of differences was analyzed using the Kruskal-Wallis test. Calculations were made for the seasons (spring, summer, autumn, and winter), growing season, and year to determine the local climate features of the mire. Microclimates were characterized based on the entire investigation period. Statistical analyses were carried out in R program using "stats" (R Core Team 2020) and "ggplot2" (Wickham 2016) packages. The results were visualized using the Grapher application (Golden Software, LLC).

\section{Results}

\section{Differences in air temperature and humidity between the mire and the open site}

The years 2012-2015 were found to be warmer than the average of 1967-2015 (Bartczak et al. 2019). We observed a significant microclimatic separation between the mire and the reference site in the open area. Although the daily course of air temperature and humidity in the mire and the open site showed the same trends, the values were different. The mire was significantly cooler than the open site due to 
a higher decline in nighttime air temperatures. The differences in the air temperatures were more pronounced near the ground $(30 \mathrm{~cm})$ compared to that at the height of $150 \mathrm{~cm}$, and were influenced by seasonal patterns and weather conditions. Among the temperature parameters, the largest differences were found in the values of minimal temperature ( $\left.T_{\text {min }}\right)$. The median difference in $T_{\min }$ was $3.9^{\circ} \mathrm{C}$ near the ground and $1.4{ }^{\circ} \mathrm{C}$ at the height of $150 \mathrm{~cm}$ for a year, with the maximum temperature difference in summer reaching $9.8^{\circ} \mathrm{C}$ in June (Fig. 2A, Table 1). In winter, the values of $T_{\min }$ were mostly higher in the mire than in the reference site, owing to snow cover. The mean air temperature at the mire was also lower by $0.81{ }^{\circ} \mathrm{C}$ near the ground and by $0.54{ }^{\circ} \mathrm{C}$ at the height of $150 \mathrm{~cm}$ for a year. In summer, the mire was cooler by $1.18{ }^{\circ} \mathrm{C}$ at $30 \mathrm{~cm}$ and by $0.92^{\circ} \mathrm{C}$ at $150 \mathrm{~cm}$, which was typical of $T_{\text {mean }}$. The maximum temperature of the mire recorded near the ground was higher by $1.9^{\circ} \mathrm{C}$, while no significant difference was noted in the temperature recorded at the height of $150 \mathrm{~cm}$ (Table 1).

The mean VPD value $\left(\mathrm{VPD}_{\text {mean }}\right)$ was lower at the mire compared to the open site in averaged differences. The average annual difference of $\mathrm{VPD}_{\text {mean }}$ was $0.32 \mathrm{hPa}$ at the height of $30 \mathrm{~cm}$ and $0.54 \mathrm{hPa}$ at $150 \mathrm{~cm}$, and the largest differences occurred during the summer season, with $0.89 \mathrm{hPa}$ at $30 \mathrm{~cm}$ and $1.29 \mathrm{hPa}$ at $150 \mathrm{~cm}$ (Fig. 2B). The maximum VPD $\left(\mathrm{VPD}_{\max }\right)$, which occurred during the warmest time of a day, showed variation in differences. At the height of $150 \mathrm{~cm}, \mathrm{VPD}_{\max }$ was lower at the mire compared to the open site, but at $30 \mathrm{~cm}$ the value was higher. The average annual difference of $\mathrm{VPD}_{\max }$ at $30 \mathrm{~cm}$ was $2.05 \mathrm{hPa}$, and $3.36 \mathrm{hPa}$ in the growing season, while in July the difference reached almost $15.0 \mathrm{hPa}$ (Fig. 2B). At $150 \mathrm{~cm}, \mathrm{VPD}_{\max }$ was lower by $0.49 \mathrm{hPa}$ averaged in a year and $1.44 \mathrm{hPa}$ in summer.

At the mire, ground frosts $\left(T_{\min }<0.0{ }^{\circ} \mathrm{C} ; T_{\max }>0.0{ }^{\circ} \mathrm{C}\right)$ at the height of $30 \mathrm{~cm}$ were recorded for $42.4 \%$ days, while at the open site they were recorded for $21.0 \%$ days of the year (Fig. 3). Ground frosts were observed in every season, even in summer, at the mire and averaged for $8.0 \%$ days, whereas at the open site they were not recorded at all. Thermal resources defined based on the GDD $\left(T_{\text {base }}=0{ }^{\circ} \mathrm{C}\right)$ index were lower by $7.0 \%$ at the height of $30 \mathrm{~cm}$ (range $7-10 \%$ ) and by $8 \%$ at $150 \mathrm{~cm}$ (range 5-9\%) at the mire (average $=3244$ GDD $30 \mathrm{~cm}$ and 3247 GDD150cm, respectively) compared to the open site.

\section{Diversity of microclimates at the Linje mire}

A significant difference in microclimates was observed between the studied microsites (MS1-MS5). We found the highest sum of incoming PAR for MS1, which was identified as a site where incoming PAR completely reached the ground. Based on this, the relative reduction of incoming solar energy to the ground was calculated in the other microsites (18\% for MS4, 24\% for MS3, 49\% for MS2, and $73 \%$ for MS5). The differences in the shading of microsites were reflected by other elements of microclimate. The highest daily mean temperature was observed for the most open site MS1 and for slightly shaded sites MS3 and MS4 (Table 2). The value of $T_{\text {mean }}$ was the lowest in the shadiest sites MS2 and MS5, but the differences between the sites were statistically insignificant. Extreme air temperatures, both minimum $\left(T_{\min }\right)$ and maximum $\left(T_{\max }\right)$, showed highly significant differences. Average and absolute $T_{\min }$ were twice as low at the most open sites (MS1, MS3, and MS4), where the average values ranged from 2.4 to $3.0^{\circ} \mathrm{C}$, while in the shaded sites (MS2 and MS5) the values reached $4.3-6.4^{\circ} \mathrm{C}$. The highest maximum temperature was noted in the partly shaded sites (MS3 and MS4), where the absolute values were $39.5-40.0{ }^{\circ} \mathrm{C}$, while in the most shaded sites (MS2 and MS5) the maximum temperature was $33.7-33.8^{\circ} \mathrm{C}$. DTR was found to be the smallest for the sites MS2 and MS5. Heat accumulation in microhabitats was determined by GDD $\left(T_{\text {base }}=0{ }^{\circ} \mathrm{C}\right)$, based on which MS4 was identified as the warmest and MS2 as the coldest (Table 2).

Analysis of relative humidity and VPD indicated that MS2 and MS5 sites had the highest humidity. The average daily relative humidity $\left(\mathrm{RH}_{\text {mean }}\right)$ was $85.5-86.6 \%$ and average VPD ( $\mathrm{VPD}_{\text {mean }}$ ) was $2.8-2.9 \mathrm{hPa}$. The $\mathrm{LW}$ duration was the longest in MS2 (3327 h), while in MS5 it was $2636 \mathrm{~h}$ for the investigated period. The driest places were MS1 and MS3, where the daily average relative humidity was 78.5-79.6\% and VPD was $5.1 \mathrm{hPa}$. More importantly, the 95th percentile of the daily average VPD was $15.0 \mathrm{hPa}$ in MS1, MS3, and MS4 and only 7.1-8.0 hPa in MS2 and MS5 (Fig. 4). The LW duration was the shortest in MS4 (2055 h). The microsites MS2 and MS5 were also found to be the wettest based on the values of WTD. The average groundwater level in these sites was 9.1 and $6.0 \mathrm{~cm}$, respectively. MS4 located by the dune was identified as the driest site with an average WTD of $20.6 \mathrm{~cm}$.

The differences in microclimate between the studied microsites were especially pronounced on hot and dry days, as occurred from July 23 to 28,2012 . The daily time courses of air temperature and VPD recorded at each microsite are plotted in Fig. 5. The differences in maximum daytime air temperatures between the most shaded (MS2 and MS5) and more open microsites (MS1, MS3, and MS4) ranged from 5.1 to $8.2{ }^{\circ} \mathrm{C}$ (an average difference of $6.9^{\circ} \mathrm{C}$ ). In the open microsites, greater heat emission resulted in a higher decline in air temperature during the night and early morning hours, and on July 23, ground frosts occurred at MS1 and MS3, while $T_{\min }$ at MS5 was $6.0^{\circ} \mathrm{C}$. Maximal VPD was found to be much higher in the open microsites (MS1, MS3, and MS4) reaching a value of $46.1 \mathrm{hPa}(\mathrm{MH} 4)$, while in the shaded microsites (MS2 and MS5) it was approximately $20.0 \mathrm{hPa}$. 

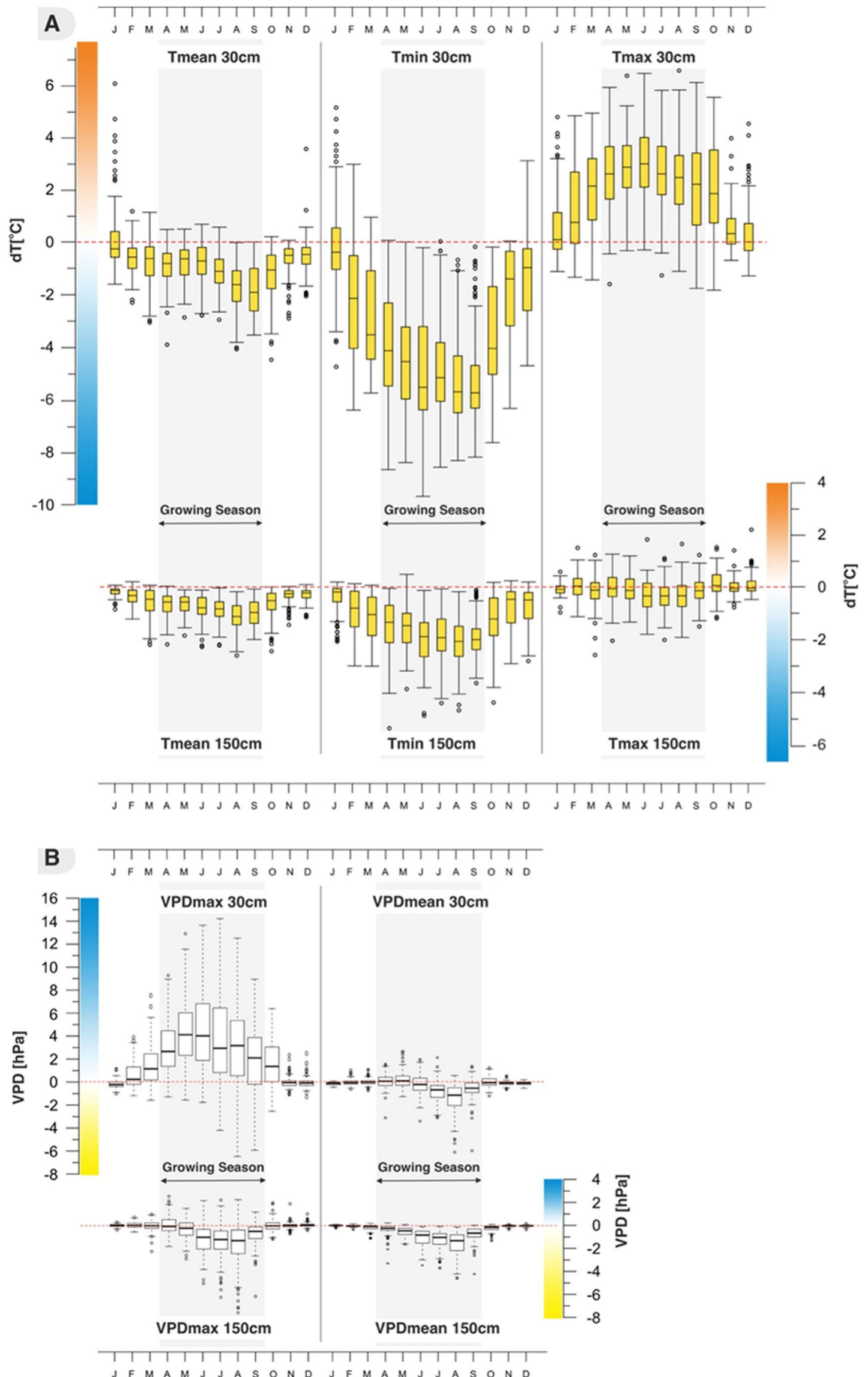
४Fig. 2 Monthly differences in A daily air temperature (mean, minimum, and maximum) and B VPD (mean and maximum) at a height of 30 and $150 \mathrm{~cm}$ between the mire and the open (reference) site for the period from April 2, 2012, to December 17, 2015

\section{Discussion}

\section{Climatic distinctiveness of the mire}

According to Dobrowski (2010), refugia are characterized by climates that are decoupled from regional averages. In this study, we found that the mire was significantly cooler than the reference site. Even though the differences in mean annual temperatures between the mire and the reference site were relatively small (less than $1{ }^{\circ} \mathrm{C}$; Table 1 ), they resulted from large differences in the minimum daily air temperature, especially during the growing season which is the most important for living organisms. The $T_{\min }$ and $T_{\max }$ values of the reference site and the mire differed by several degrees. Other studies conducted in raised bogs revealed that they differ from the surrounding landscape in both lower and higher temperature extremes, and were characterized by a higher chance of ground frost in summer nights and a lower mean temperature (Eggelsman 1980; Ermich 1972; Peus 1932).

The isothermal map of the mean annual air temperature of Poland shows that a temperature difference of $1{ }^{\circ} \mathrm{C}$ reflects a spatial shift to the north or east by about several dozen kilometers toward a cooler climate (Climate Maps of Poland, Institute of Meteorology and Water Management, NRI; https://klimat.imgw.pl/pl/climate-maps). Thus, geographically speaking, the local climate of the mire corresponds to the regional average for cooler areas.

It was observed that the local climate and microclimates in the mire were influenced by the synergy of factors, including topography, wetness conditions, and vegetation composition. The location of the mire in a small depression, its relatively small area (about $6.0 \mathrm{ha}$ ), and the surrounding forest favor the formation of a cold air pool (Geiger et al. 1995; Lundquist 2008), where cooler and heavier air is held closer to the ground, with warmer air above.

Many peatlands in Central Europe are at a similar location (Tobolski 2000), and thus may be characterized by similar local climate features.

The composition and properties of vegetation, as well as the hydrological conditions which are dependent on the annual sum and distribution of precipitation, are undeniably one of the most important factors influencing microclimate. Postglacial peatlands in Central Europe are mainly dominated by Sphagnum moss. A several-meter layer of such sediments can be found in some of these peatlands, as in our study site. However, an acrotelm, which is the active layer, responds to meteorological changes through changing groundwater levels (Morris et al. 2011; Tobolski 2000).
Apart from plant composition, which is influenced by a variety of factors, water level and surface wetness determine the thermal properties of Sphagnum mosses (Ellenberg 1988).

Due to the extremely low heat capacity and thermal conductivity of dry Sphagnum, heat is transferred into and out of the dry peat surface at a slower rate than wet peat (Loranty et al. 2018; Petrone et al. 2004). Furthermore, dry peat mosses have a poor capillary uptake capacity and cannot draw water from deeper layers (Romanov 1968). Thus, the surface layer formed by Sphagnum mosses acts as an insulating layer filled with air, contributing to an increase in albedo (Price 1996). It protects the deeper layers from water loss and heating up, thereby preventing heat transfer from these layers to the surface during cooling at night. The Linje peatland was drained at the end of the nineteenth century (Słowińska et al. 2010). The remains of ditches still slightly increase water outflow from the peatland, increasing the interannual and seasonal hydrological instability. Even short periods of no rainfall in summer cause a significant decrease in groundwater level, resulting in drying of the surface layer (Samson et al. 2018; Słowińska et al. 2010; Słowińska 2016). Therefore, especially in summer, air temperature in the mire fluctuated more than at the reference station. The dry surface of Sphagnum moss strongly heated during the day, which led to higher daily maximum air temperatures, and the surface cooled down at night, resulting in significantly lower daily minimum air temperatures. The higher air temperature was responsible for the higher air VPD, which in turn determines the moss evaporation rate (Heijmans et al. 2004). Heterogeneous vegetation structure influences the microtopography of the mire which has a cascading effect on physical parameters as well as microbiology (Fournier et al. 2020; Malhotra et al. 2016; Rydin and Jeglum 2013).

\section{Microclimatic differences on the peatland-effect of shading, vegetation, and wetness}

The microsites analyzed in our study represented four different types of vegetation. Two of the studied microsites (MS2 and MS5) were shaded from direct sunlight by trees with a high groundwater level. The trees and the south and west edge of the mire, which was right next to the forest line, obscured the horizon, thus directly influencing the light conditions compared to the other more open microsites (MS2, MS3, and MS4). The incoming solar energy was therefore limited in MS2 and MS5. The reduced sky view factor of the sites beneath the canopy reduced long-wave radiative losses, and as a result, the daily air temperature ranges of the shaded sites were smaller than those in the open sites. Additionally, the shaded sites had a high groundwater level, with wet mosses having greater heat capacity and thermal conductivity than dry ones, 


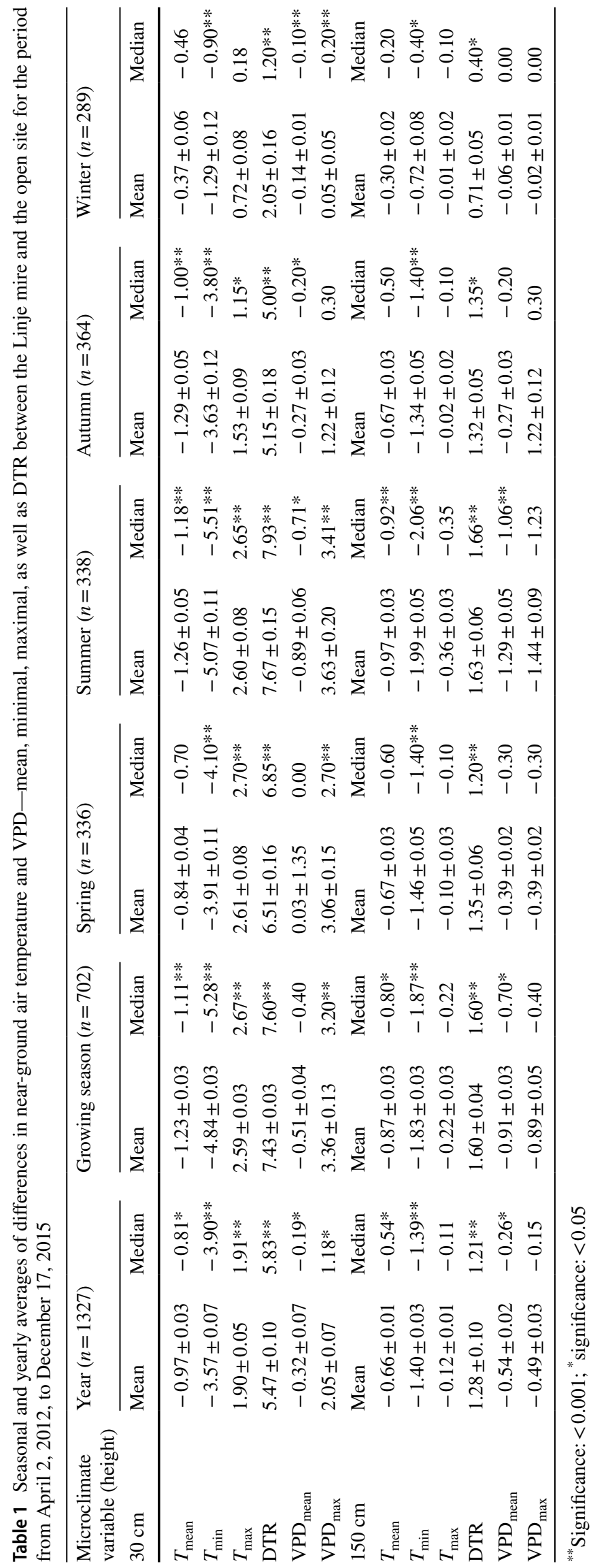




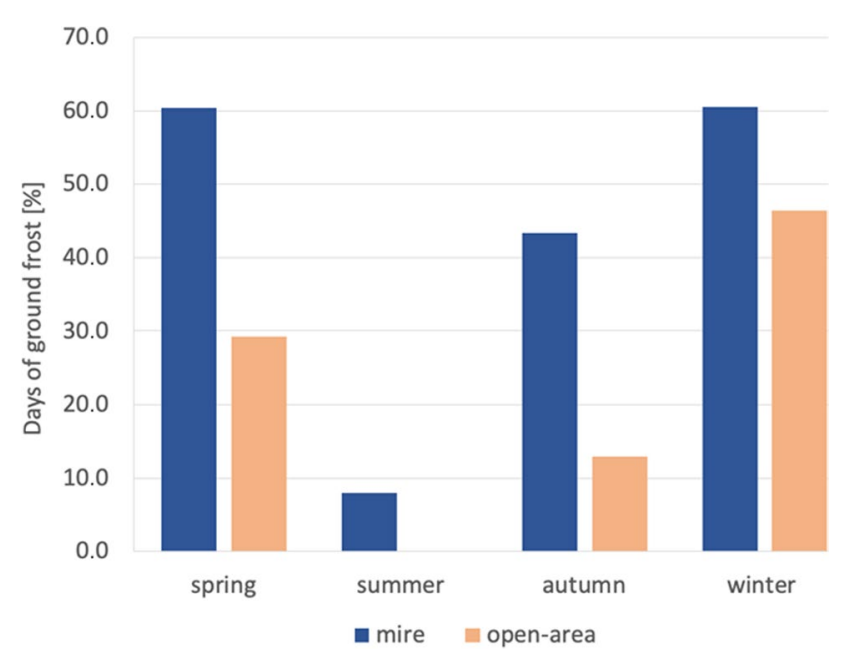

Fig. 3 Days of ground frost in seasons and years at the Linje mire and the open site for the period from April 2, 2012, to December 17, 2015

and therefore, the diurnal air temperature fluctuations were lower. At the open microsites, higher solar radiation contributed to higher air temperature and thus lower air humidity during the daytime. At night, temperature and humidity were higher in the shaded stands. Wet and shaded sites having a high groundwater level had lower amplitudes of daily air temperature, owing to the lower maximum and higher minimum temperatures. In general, the studied sites were cooler during the investigation period. The data obtained from the LW sensors indicated that the shaded stands were also wetter in terms of air humidity and due to the presence of dew deposits. At open microsites, VPD was almost twice as high, potentially causing greater ecological stress for microorganisms and plants (Jassey et al. 2018; Pappas et al. 2020). Moreover, the maximum air temperature in these microsites was $4{ }^{\circ} \mathrm{C}$ higher compared to the shaded sites. Our findings show that the differences in microclimate between the sites located close to each other may significantly vary, and based on a study by Heijmans et al. (2004), it can be concluded that microclimate is the primary factor determining moss evaporation rates.

According to climate change projections, the median of climatic water balance (difference in precipitation and evaporation) will decrease from $-32 \mathrm{~mm}$ (1971-2000) to $-50 \mathrm{~mm}$ (2061-2090) (Szwed et al., 2010). In the case of peatlands fed by rain-derived water (ombrogenic ones) and shallow groundwater (topogenic ones), the projected climate change will cause a water-level drawdown and the entry of shrubs and trees due to succession (Laiho et al., 2003). This will change a number of relationships, including microclimatic conditions, of both ground and nearground layer (Heijmans et al. 2013; Laiho et al. 2003). Our study showed that the shaded microsites had a completely different microclimate. However, it is difficult to determine which factor — shade or high groundwater level—was more important in keeping them cool.
Table 2 Microclimatic characteristics of microsites during the period from April 15 to November 9, 2012 (except June 14-July 8)

\begin{tabular}{|c|c|c|c|c|c|c|}
\hline \multicolumn{2}{|c|}{ Microclimate variables } & \multicolumn{5}{|l|}{ Microsites } \\
\hline & & MS1 & MS2 & MS3 & MS4 & MS5 \\
\hline \multirow[t]{2}{*}{$\operatorname{PAR}[\mathrm{MJ}]$} & $\operatorname{sum}^{* *}$ & 1095.7 & 554.6 & 838.1 & 897.2 & 294.2 \\
\hline & mean & $12.6 \pm 0.4$ & $11.6 \pm 0.4$ & $12.5 \pm 0.4$ & $12.3 \pm 0.4$ & $12.2 \pm 0.4$ \\
\hline \multirow[t]{5}{*}{$T_{\text {air }}\left[{ }^{\circ} \mathrm{C}\right]$} & $\min _{\mathrm{avg}}{ }^{* *}$ & $2.4 \pm 0.4$ & $4.3 \pm 0.4$ & $2.5 \pm 0.4$ & $3.0 \pm 0.4$ & $6.4 \pm 0.3$ \\
\hline & $\min _{\mathrm{abs}}$ & -12.6 & -8.2 & -11.3 & -11.0 & -6.2 \\
\hline & $\max _{\mathrm{avg}}{ }^{* *}$ & $22.3 \pm 0.5$ & $19.3 \pm 0.5$ & $23.2 \pm 0.6$ & $23.7 \pm 0.6$ & $19.0 \pm 0.5$ \\
\hline & $\max _{\mathrm{abs}}$ & 38.0 & 33.7 & 39.5 & 40.0 & 33.8 \\
\hline & $\mathrm{DR}_{\mathrm{avg}}$ & $19.8 \pm 0.5$ & $15.1 \pm 0.4$ & $20.7 \pm 0.5$ & $20.7 \pm 0.5$ & $12.7 \pm 0.4$ \\
\hline \multirow[t]{2}{*}{$\operatorname{GDD}\left[T_{\text {base }}=0^{\circ}\right]$} & sum & 2276 & 2173 & 2359 & 2456 & 2340 \\
\hline & mean** & $78.5 \pm 0.7$ & $86.6 \pm 0.7$ & $79.6 \pm 0.7$ & $80.3 \pm 0.6$ & $85.5 \pm 0.7$ \\
\hline \multirow[t]{4}{*}{$\mathrm{RH}[\%]$} & $\min _{\mathrm{avg}} * *$ & $50.6 \pm 1.1$ & $67.5 \pm 1.4$ & $50.6 \pm 1.3$ & $49.7 \pm 1.3$ & $65.3 \pm 1.3$ \\
\hline & $\max _{\text {avg }} * *$ & $96.1 \pm 0.1$ & $97.1 \pm 0.1$ & $96.9 \pm 0.1$ & $96.2 \pm 0.1$ & $96.6 \pm 0.1$ \\
\hline & $\mathrm{DR}_{\mathrm{avg}} * *$ & $45.5 \pm 1.1$ & $29.6 \pm 1.3$ & $46.3 \pm 1.3$ & $46.6 \pm 1.3$ & $31.3 \pm 1.2$ \\
\hline & mean** & $5.1 \pm 0.3$ & $2.8 \pm 0.2$ & $5.1 \pm 0.3$ & $4.9 \pm 0.3$ & $2.9 \pm 0.2$ \\
\hline \multirow[t]{3}{*}{ VPD $[\mathrm{hPa}]$} & $\min _{\mathrm{avg}} * *$ & $0.4 \pm 0.0$ & $0.3 \pm 0.0$ & $0.3 \pm 0.0$ & $0.4 \pm 0.0$ & $0.4 \pm 0.0$ \\
\hline & $\max _{\mathrm{avg}} * *$ & $15.4 \pm 0.7$ & $9.2 \pm 0.6$ & $17.0 \pm 0.9$ & $18.0 \pm 0.9$ & $9.4 \pm 0.6$ \\
\hline & $\mathrm{DR}_{\mathrm{avg}} * *$ & $15.1 \pm 0.7$ & $8.9 \pm 0.6$ & $16.7 \pm 0.9$ & $17.6 \pm 0.9$ & $8.9 \pm 0.5$ \\
\hline LW [h] & $\operatorname{sum}^{* *}$ & 2169 & 3327 & 2527 & 2055 & 2636 \\
\hline WTD $[\mathrm{cm}]$ & mean & 11.9 & 9.1 & 18.9 & 20.6 & 6.0 \\
\hline
\end{tabular}

${ }^{* *}$ Significance: $<0.001 ;$ " significance: $<0.05$ 

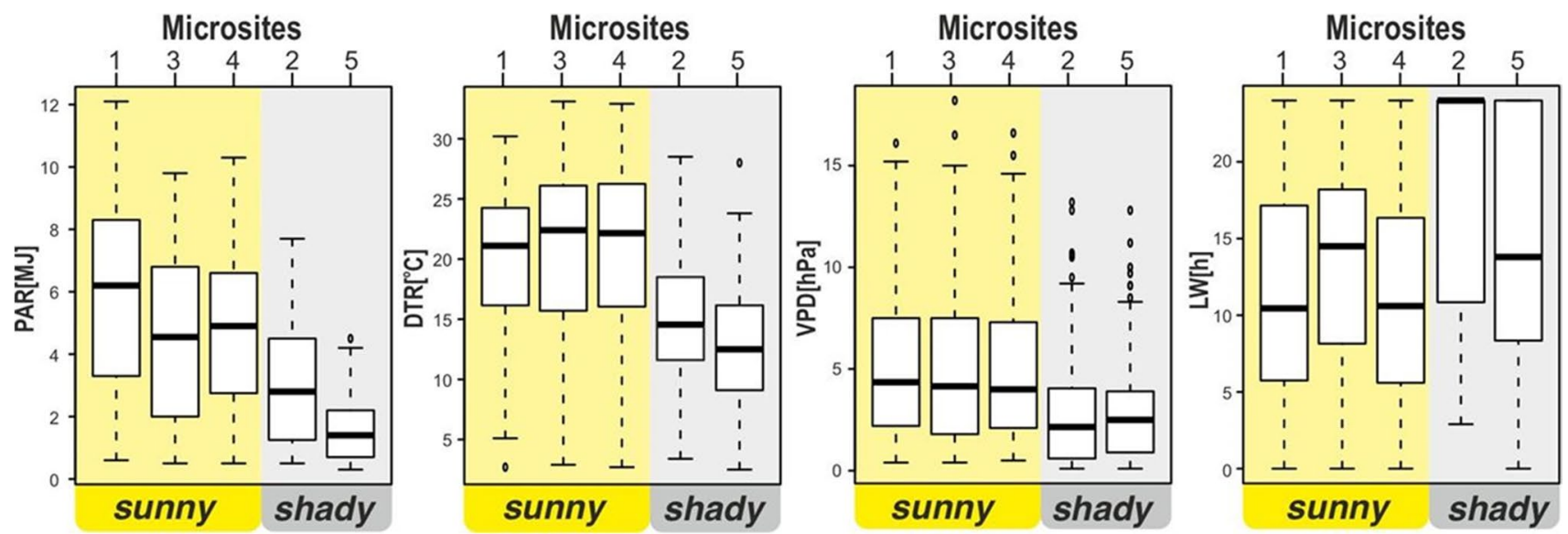

Fig. 4 Daily sum of PAR, DTR, VPD, and LW for the period from April 15 to November 9, 2012 (except June 14 to July 8)

Fig. 5 Daily time course of air temperature and VPD at the microsites MS1-MS5, during July 23-28, 2012
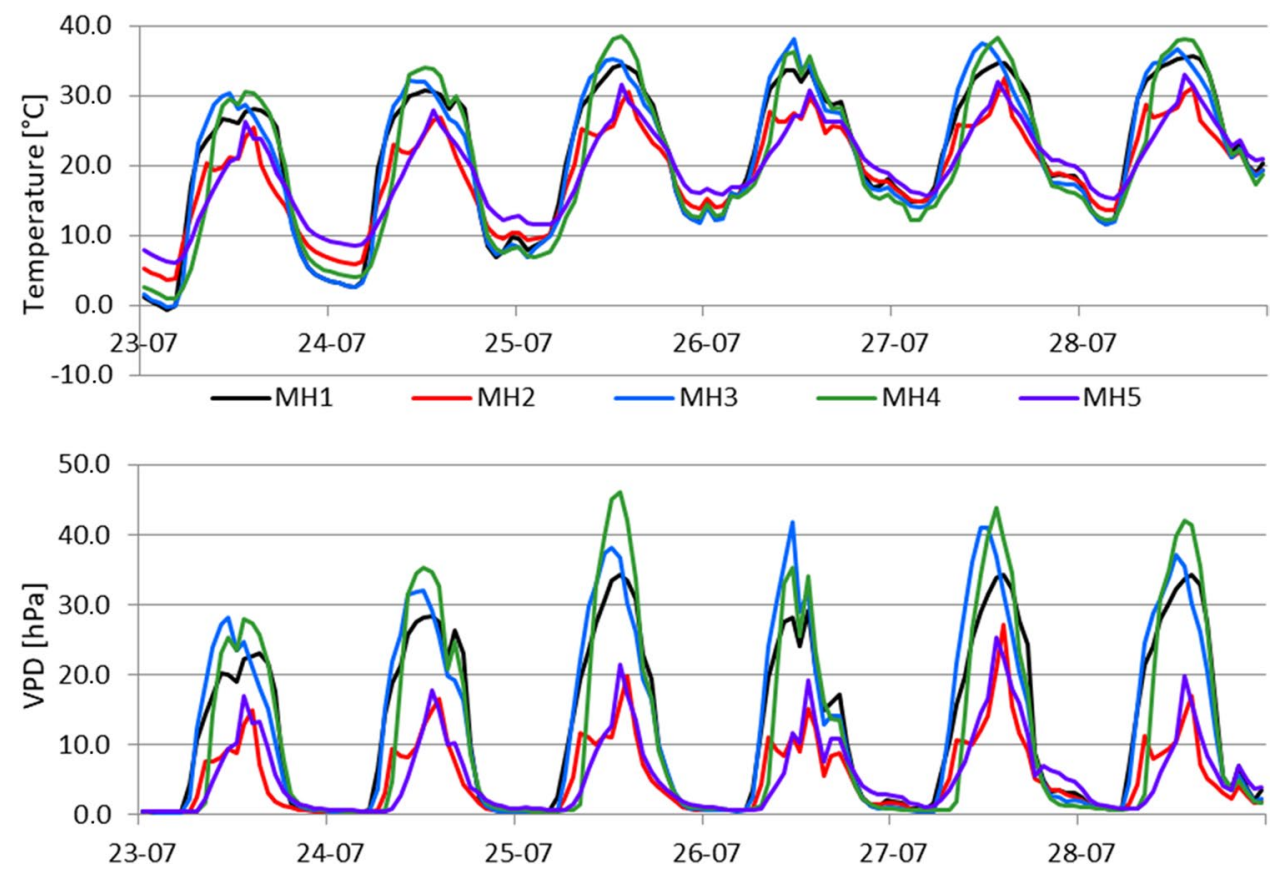

\section{Peatlands as climate refugia}

The specific local climate of peatlands is determined by various factors-including topography, water conditions, vegetation composition, and specific climatic conditions associated with them (Eggelsman 1980; Ermich 1972; Peus 1932). Due to their unique features, peatlands often act as refugia for glacial relicts such as B. nana or Rubus chamaemorus as well as insects such as Somatochlora alpestris (Głowaciński and Nowacki 2004; Zarzycki and Mirek 2006). The species B. nana has been documented in the peat core at our site since the period of Younger Dryas around 12 thousand years ago (Noryśkiewicz 2005).
However, a more in-depth investigation is required to determine the factors enabling the survival of this species.

Human activities, such as afforestation and peat extraction, disrupt the natural functioning of peatlands (Euców et al. 2020; Lamentowicz et al. 2019b). Disturbed peatlands are hydrologically unstable and respond more quickly to normal seasonal and interannual changes in meteorological conditions. Moreover, higher climate fluctuations and frequent extreme events, including droughts, will undoubtedly have a negative impact on the functioning of peatlands (Gallego-Sala et al. 2018; Loisel et al. 2021; Swindles et al. 2019). This can result in peatlands overgrowing, and necessitating active management for raising the groundwater level or removing trees to keep them relatively stable. Maintaining stable water 
conditions in peatlands in this climate zone, however, will be a major challenge. Swindles et al. (2019) showed that the paleohydrological record from the last 300 years indicates a decreasing trend of the groundwater table in European peatlands, which is attributed to climate warming and human activities. Long-term persistence of a low groundwater level results in tree encroachment (Heijmans et al. 2013), which drastically alters microclimates and other processes (Davis et al. 2019; Limpens et al. 2014; Stralberg et al. 2020; Winter 2000).

\section{Importance of microclimatological research for paleoecology}

To interpret the findings of paleoecological research, it is important to study the ecology of peatlands as well as define their resilience to recent climate changes (Hapsari et al. 2018; Harris et al. 2020; Page and Baird 2016). For example, testate amoebae are one of the proxies used in reconstruction and bioindicators (Mitchell et al. 2007a, 2007b) and can be used to reconstruct past hydrological dynamics (Lamentowicz and Mitchell 2005; Lamentowicz et al. 2015). However, these organisms may respond to meteorological factors, including the amount of incoming solar radiation (Herbert et al. 2018; Jassey et al. 2015; Lamentowicz et al. 2020; Marcisz et al. 2014). Only through detailed ecological research on the microbial communities of peatland, including meteorological measurements in microscale, one can answer the question of how their functional traits vary in time and space (Marcisz et al. 2020).

In this study, paleoecological results showed that B. nana was present in the mire during the Late Glacial period and throughout the Holocene (Noryśkiewicz et al. 2005). Despite significant climatic changes during that time period, which directly as well as indirectly influenced the development and transformation of the mire from a rich fen (with a mix of Sphagnum and vascular plants) to a poor fen (dominated by Sphagnum), B. nana has survived to the present day (Marcisz et al., 2015). The results of our study showed that such transformation was possible through a synergy of individual terrain elements, and was mediated by physical refugia features (e.g., peatland located on the boundaries of two watersheds, steep ice melt-out forms) and ecosystem-protected mechanism (climatic buffering, light and hydrological competition) (Shur et al. 2007; Stralberg et al. 2020; Waddington et al. 2015).

A comprehensive understanding of long-term peatland monitoring will allow bridging the gap between ecology and paleoecology. This knowledge may help us better interpret the reconstructed data from the peat archive. By combining reconstruction, observation, and experimentation, we can go beyond and determine the tipping points for the ecosystems under study (Lamentowicz et al. 2016, 2019a; Seddon et al. 2014). Furthermore, the framework of monitoring and the results presented here can be readily extended to phenological or microbiological biodiversity research. A real data example was used to demonstrate our approach to define the characteristics and heterogeneity of peatland microclimates as well as the inertia/mitigation of climate changes.

\section{Conclusions}

Our long-term measurements of meteorological parameters on the peatland provided a novel insight into the local climate features in the context of seasonality of this ecosystem. We investigated the unique climate features and microclimate differences in a mid-forest peatland located in northern Poland, in terms of shading due to shrubs and trees and wetness effects.

The studied peatland was cooler on average than the open reference site, due to higher drops in night air temperature. During the growing season, the surface layer of the peat often dried out, causing changes in the physical properties of mosses and greater fluctuations in diurnal air temperature at the ground layer. The site was a drained object that reacted quickly to changes in meteorological conditions, especially the amount and distribution of precipitation and temperature during growing seasons, both of which largely influence the evapotranspiration rate. The microclimatic conditions of the peatland were significantly affected by WTDs and shade. Wet and shaded sites were cooler than those with a lower water level and receiving a higher amount of solar radiation, and were also less exposed to extreme daily temperatures. This is important in the context of climate change, as an increase in global air temperature will lead to an increase in evapotranspiration rate, and subsequently a decrease in the water table in peatlands directly dependent on meteorological conditions. Overgrowth of trees is a natural effect that lowers the groundwater level, resulting in an increase in shading and a secondary impact on evapotranspiration in the sites. Our research is part of the discussion on the importance of microclimatic studies of ecosystems in climate change. Although the results presented here are specific to one mire, and were obtained from a case study, they can be applied to similar objects on earth in similar physiographic conditions. They can also be used to model species distribution.

The trajectory of the earth system is currently changing as a result of dramatic human-driven climate changes (Steffen et al. 2018). These climate changes have irreversible consequences for the ecosystems, society, and economy. Therefore, it is critical to understand under what conditions ecosystem function can be corrected by management strategies in the future. The findings presented in this paper make 
an important contribution to our understanding of the functioning of peatlands in time and space.

Supplementary Information The online version contains supplementary material available at https://doi.org/10.1007/s00484-022-02240-2.

Author contribution Sandra Słowińska conceived and designed the project, analyzed the data, prepared figures and tables, authored and reviewed drafts of the paper, and approved the final draft. Katarzyna Marcisz, Mariusz Lamentowicz, and Michał Słowiński authored and reviewed drafts of the paper and approved the final draft.

Funding This work was financed by the National Science Centre, Poland (grant no. NN306060940).

\section{Declarations}

Conflict of interest The authors declare no competing interests.

Open Access This article is licensed under a Creative Commons Attribution 4.0 International License, which permits use, sharing, adaptation, distribution and reproduction in any medium or format, as long as you give appropriate credit to the original author(s) and the source, provide a link to the Creative Commons licence, and indicate if changes were made. The images or other third party material in this article are included in the article's Creative Commons licence, unless indicated otherwise in a credit line to the material. If material is not included in the article's Creative Commons licence and your intended use is not permitted by statutory regulation or exceeds the permitted use, you will need to obtain permission directly from the copyright holder. To view a copy of this licence, visit http://creativecommons.org/licenses/by/4.0/.

\section{References}

Allen RG, Pereira LS, Raes D, Smith M (1998) Crop evapotranspiration-guidelines for computing crop water requirements-FAO Irrigation and drainage paper 56.

Amesbury MJ, Gallego-Sala A, Loisel J (2019) Peatlands as prolific carbon sinks. Nat Geosci. https://doi.org/10.1038/ s41561-019-0455-y

Ashcroft MB (2010) Identifying refugia from climate change. J Biogeogr 37(8):1407-1413. https://doi.org/10.1111/j.1365-2699. 2010.02300.x

Ashcroft MB, Gollan JR (2013) The sensitivity of topoclimatic models to fine-scale microclimatic variability and the relevance for ecological studies. Theoret Appl Climatol 114(1-2):281-289. https://doi.org/10.1007/s00704-013-0841-0

Baldocchi D, Chu H, Reichstein M (2018) Inter-annual variability of net and gross ecosystem carbon fluxes: a review. Agric for Meteorol 249:520-533. https://doi.org/10.1016/j.agrformet.2017.05. 015

Bartczak A, Słowińska S, Tyszkowski S, Kramkowski M, Kaczmarek H, Kordowski J, Słowiński M (2019) Ecohydrological changes and resilience of a shallow lake ecosystem under intense human pressure and recent climate change. Water 11 (1). https://doi.org/ 10.3390/w11010032

Bertrand R, Lenoir J, Piedallu C, Riofrio-Dillon G, de Ruffray P, Vidal C, Pierrat JC, Gegout JC (2011) Changes in plant community composition lag behind climate warming in lowland forests. Nature 479(7374):517-520. https://doi.org/10.1038/ nature 10548
Birks HJ, Birks HH (2004) The rise and fall of forests. Science 305(5683):484-485. https://doi.org/10.1126/science.1101357

Bramer I, Anderson BJ, Bennie J, Bladon AJ, De Frenne P, Hemming D, Hill RA, Kearney MR, Körner C, Korstjens AH, Lenoir J, Maclean IMD, Marsh CD, Morecroft MD, Ohlemüller R, Slater HD, Suggitt AJ, Zellweger F, Gillingham PK (2018) Advances in monitoring and modelling climate at ecologically relevant scales. In: Next generation biomonitoring: Part 1. Adv Ecol Res 101-161. https://doi.org/10.1016/bs.aecr.2017.12.005

Buttler A, Robroek BJM, Laggoun-Défarge F, Jassey VEJ, Pochelon C, Bernard G, Delarue F, Gogo S, Mariotte P, Mitchell EAD, Bragazza L, Morgan J (2015) Experimental warming interacts with soil moisture to discriminate plant responses in an ombrotrophic peatland. J Veg Sci 26(5):964-974. https://doi.org/10. 1111/jvs.12296

Charman D (2002) Peatlands and environmental change. Wiley

Chen J, Franklin JF, Spies TA (1993) Contrasting microclimates among clearcut, edge, and interior of old-growth Douglas-fir forest. Agric for Meteorol 63(3-4):219-237. https://doi.org/10.1016/ 0168-1923(93)90061-1

Chronakova A, Barta J, Kastovska E, Urbanova Z, Picek T (2019) Spatial heterogeneity of belowground microbial communities linked to peatland microhabitats with different plant dominants. FEMS Microbiol Ecol 95 (9). https://doi.org/10.1093/femsec/fiz130

Davis KT, Dobrowski SZ, Higuera PE, Holden ZA, Veblen TT, Rother MT, Parks SA, Sala A, Maneta MP (2019) Wildfires and climate change push low-elevation forests across a critical climate threshold for tree regeneration. Proc Natl Acad Sci U S A. https://doi. org/10.1073/pnas.1815107116

De Frenne P, Rodriguez-Sanchez F, Coomes DA, Baeten L, Verstraeten G, Vellend M, Bernhardt-Romermann M, Brown CD, Brunet J, Cornelis J, Decocq GM, Dierschke H, Eriksson O, Gilliam FS, Hedl R, Heinken T, Hermy M, Hommel P, Jenkins MA, Kelly DL, Kirby KJ, Mitchell FJ, Naaf T, Newman M, Peterken G, Petrik P, Schultz J, Sonnier G, Van Calster H, Waller DM, Walther GR, White PS, Woods KD, Wulf M, Graae BJ, Verheyen K (2013) Microclimate moderates plant responses to macroclimate warming. Proc Natl Acad Sci U S A 110(46):18561-18565. https://doi.org/10.1073/pnas.1311190110

De Frenne P, Zellweger F, Rodriguez-Sanchez F, Scheffers BR, Hylander K, Luoto M, Vellend M, Verheyen K, Lenoir J (2019) Global buffering of temperatures under forest canopies. Nat EcolEvol. https://doi.org/10.1038/s41559-019-0842-1

Delarue F, Laggoun-Défarge F, Buttler A, Gogo S, Jassey VEJ, Disnar J-R (2011) Effects of short-term ecosystem experimental warming on water-extractable organic matter in an ombrotrophic Sphagnum peatland (Le Forbonnet, France). Org Geochem 42(9):1016-1024. https://doi.org/10.1016/j.orggeochem.2011. 07.005

Dieleman CM, Branfireun BA, McLaughlin JW, Lindo Z (2015) Enhanced carbon release under future climate conditions in a peatland mesocosm experiment: the role of phenolic compounds. Plant Soil 400(1-2):81-91. https://doi.org/10.1007/ s11104-015-2713-0

Dítě D, Hájek M, Svitková I, Košuthová A, Šoltés R, Kliment J (2018) Glacial-relict symptoms in the Western Carpathian flora. Folia Geobot 53:277-300

Dobrowski SZ (2011) A climatic basis for microrefugia: the influence of terrain on climate. Glob Change Biol 17(2):1022-1035. https://doi.org/10.1111/j.1365-2486.2010.02263.x

Eggelsman R (1980) Mikroklima der Moore (in German). In: Göttlich K (ed) Moorund Torfkunde. Schweizerbart'sche Verlagsbuchhandlung, Stuttgart, pp 224-230

Ellenberg HH (1988) Vegetation ecology of Central Europe. Cambridge University Press 
Ermich K (1972) Contribution to the knowledge of the thermal conditions of the "Przymiarki" raised bog near Ludźmierz. Acta Agraria Et Silvestria, Series Silvestris XII: 21-38 (in Polish)

Fournier B, Samaritani E, Frey B, Seppey CVW, Lara E, Heger TJ, Mitchell EAD (2020) Higher spatial than seasonal variation in floodplain soil eukaryotic microbial communities. Soil Biol Biochem 147:107842. https://doi.org/10.1016/j.soilbio.2020.107842

Gallé R, Samu F, Zsigmond A-R, Gallé-Szpisjak N, Urák I (2019) Even the smallest habitat patch matters: on the fauna of peat bogs. J Insect Conserv 23(4):699-705. https://doi.org/10.1007/s10841-019-00164-8

Gallego-Sala AV, Charman DJ, Brewer S, Page SE, Prentice IC, Friedlingstein P, Moreton S, Amesbury MJ, Beilman DW, Björck S, Blyakharchuk T, Bochicchio C, Booth RK, Bunbury J, Camill P, Carless D, Chimner RA, Clifford M, Cressey E, ... Zhao Y (2018) Latitudinal limits to the predicted increase of the peatland carbon sink with warming. Nat Clim Chang. https://doi.org/10. 1038/s41558-018-0271-1

Geiger R, Aron RH, Todhunter P (1995) Influence of the underlying surface on the adjacent air layer. In: Geiger R, Aron RH, Todhunter P (eds) The climate near the ground. Vieweg+Teubner Verlag, Wiesbaden, pp 123-196. https://doi.org/10.1007/ 978-3-322-86582-3_4

Głowaciński Z, Nowacki J (2004) Polska czerwona księga zwierząt. Bezkręgowce. Instytut Ochrony Przyrody PAN \& Akademia Rolnicza im. A. Cieszkowskiego, Kraków: (in Polish)

Gubler M, Henne PD, Schwörer C, Boltshauser-Kaltenrieder P, Lotter AF, Brönnimann S, Tinner W (2018) Microclimatic gradients provide evidence for a glacial refugium for temperate trees in a sheltered hilly landscape of Northern Italy. J Biogeogr. https:// doi.org/10.1111/jbi.13426

Hajek M, Horsak M, Hajkova P, Dite D (2006) Habitat diversity of central European fens in relation to environmental gradients and an effort to standardise fen terminology in ecological studies. Perspect Plant Ecol Evol Syst 8(2):97-114. https://doi.org/10. 1016/j.ppees.2006.08.002

Hałas S (2007) Microclimate of the Linje mire and its influence on fluctuations in the water table depths. Master thesis. Kazimierz Wielki University, Bydgoszcz, Poland

Hapsari KA, Biagioni S, Jennerjahn TC, Reimer P, Saad A, Sabiham S, Behling H, Austin A (2018) Resilience of a peatland in Central Sumatra, Indonesia to past anthropogenic disturbance: improving conservation and restoration designs using palaeoecology. J Ecol. https://doi.org/10.1111/1365-2745.13000

Harris LI, Roulet NT, Moore TR (2020) Drainage reduces the resilience of a boreal peatland. Environ Res Commun 2 (6). https:// doi.org/10.1088/2515-7620/ab9895

Heijmans MM, van der Knaap YA, Holmgren M, Limpens J (2013) Persistent versus transient tree encroachment of temperate peat bogs: effects of climate warming and drought events. Glob Chang Biol 19(7):2240-2250. https://doi.org/10.1111/gcb.12202

Heijmans MMPD, Arp WJ, Chapin FS, III (2004) Controls on moss evaporation in a boreal black spruce forest. Global Biogeochem Cycles 18 (2):GB2004. https://doi.org/10.1029/2003gb002128

Herbert RP, Peters SC, Nelson DM, Booth RK (2018) Light variability and mixotrophy: responses of testate amoeba communities and shell $\delta 13 \mathrm{C}$ values to a peatland shading experiment. Eur J Protistol. https://doi.org/10.1016/j.ejop.2018.10.005

Hojdová M, Hais M, Pokorný J (2005) Microclimate of a peat bog and of the forest in different. Silva Gabreta 11(1):13-24

Huntington HP, Danielson SL, Wiese FK, Baker M, Boveng P, Citta JJ, Robertis A, De Dickson DMS, Farley E, George JC, Iken K, Kimmel DG, Kuletz K, Ladd C, Levine R, Quakenbush L, Stabeno P, Stafford KM, Stockwell D, Wilson C (2020) Evidence suggests potential transformation of the Pacific Arctic ecosystem is underway. Nat Clim Chang. https://doi.org/10.1038/ s41558-020-0695-2
Jassey VE, Signarbieux C, Hattenschwiler S, Bragazza L, Buttler A, Delarue F, Fournier B, Gilbert D, Laggoun-Defarge F, Lara E, Mills RT, Mitchell EA, Payne RJ, Robroek BJ (2015) An unexpected role for mixotrophs in the response of peatland carbon cycling to climate warming. Sci Rep 5:16931. https://doi.org/ 10.1038/srep16931

Jassey VEJ, Reczuga MK, Zielinska M, Słowińska S, Robroek BJM, Mariotte P, Seppey CVW, Lara E, Barabach J, Słowiński M, Bragazza L, Chojnicki BH, Lamentowicz M, Mitchell EAD, Buttler A (2018) Tipping point in plant-fungal interactions under severe drought causes abrupt rise in peatland ecosystem respiration. Glob Chang Biol 24:972-986. https://doi.org/10. $1111 /$ gcb. 13928

Jones MC, Peteet DM, Kurdyla D, Guilderson T (2009) Climate and vegetation history from a 14,000-year peatland record, Kenai Peninsula, Alaska. Quatern Res 72:207-217

Juszczak R, Humphreys E, Acosta M, Michalak-Galczewska M, Kayzer D, Olejnik J (2012) Ecosystem respiration in a heterogeneous temperate peatland and its sensitivity to peat temperature and water table depth. Plant Soil 366(1-2):505-520. https://doi.org/ 10.1007/s11104-012-1441-y

Kellner E (2001) Surface energy fluxes and control of evapotranspiration from a Swedish Sphagnum mire. Agric for Meteorol 110(2):101-123. https://doi.org/10.1016/s0168-1923(01)00283-0

Kuchcik M, Błażejczyk K, Milewski P, Szmyd J (2014) Urban climate research in Warsaw: the results of microclimatic network measurements. Geogr Pol 87(4):491-504. https://doi.org/10.7163/ GPol.2014.33

Laiho R, Vasander H, Penttilä T, Laine J (2003) Dynamics of plantmediated organic matter and nutrient cycling following waterlevel drawdown in boreal peatlands. Global Biogeochem Cycles 17(2)

Lamentowicz M, Gałka M, Marcisz K, Słowiński M, KajukałoDrygalska K, Dayras MD, Jassey VEJ (2019a) Unveiling tipping points in long-term ecological records from Sphagnumdominated peatlands. Biol Lett 15 (4). https://doi.org/10.1098/ rsbl.2019.0043

Lamentowicz M, Kajukało-Drygalska K, Kołaczek P, Jassey VEJ, Gąbka M, Karpińska-Kołaczek (2020) Testate amoebae taxonomy and trait diversity are coupled along an openness and wetness gradient in pine-dominated Baltic bogs. Eur J Protistol. https://doi.org/10.1016/j.ejop.2020.125674

Lamentowicz M, Kołaczek P, Mauquoy D, Kittel P, Łokas E, Słowiński M, Jassey VEJ, Niedziółka K, Kajukało-Drygalska K, Marcisz K (2019) Always on the tipping point - a search for signals of past societies and related peatland ecosystem critical transitions during the last 6500 years in N Poland. QuaternSci Rev 225. https://doi.org/10.1016/j.quascirev.2019.105954

Lamentowicz M, Mitchell EAD (2005) The ecology of testate amoebae (Protists) in Sphagnum in north-western Poland in relation to peatland ecology. Microb Ecol 50(1):48-63. https://doi.org/10. 1007/s00248-004-0105-8

Lamentowicz M, Słowińska S, Słowiński M, Jassey VEJ, Chojnicki BH, Reczuga MK, Zielinska M, Marcisz K, Lamentowicz L, Barabach J, Samson M, Kolaczek P, Buttler A (2016) Combining short-term manipulative experiments with long-term palaeoecological investigations at high resolution to assess the response of Sphagnum peatlands to drought, fire and warming. Mires Peat 18. UNSP2010.19189MaP2016.OMB244

Lamentowicz M, Słowiński M, Marcisz K, Zielinska M, Kaliszan K, Lapshina E, Gilbert D, Buttler A, Fialkiewicz-Koziel B, Jassey VEJ, Laggoun-Defarge F, Kolaczek P (2015) Hydrological dynamics and fire history of the last 1300 years in western Siberia reconstructed from a high-resolution, ombrotrophic peat archive. Quatern Res 84(3):312-325. https://doi.org/10.1016/j. yqres.2015.09.002 
Lembrechts JJ, Nijs I, Lenoir J (2019) Incorporating microclimate into species distribution models. Ecography 42(7):1267-1279. https://doi.org/10.1111/ecog.03947

Liao X, Liu Z, Wang Y, Jin J (2013) Spatiotemporal variation in the microclimatic edge effect between wetland and farmland. J Geophys Res Atmos 118(14):7640-7650. https://doi.org/10.1002/ jgrd.50573

Limpens J, Berendse F, Blodau C, Canadell JG, Freeman C, Holden J, Roulet N, Rydin H, Schaepman-Strub G (2008) Peatlands and the carbon cycle: from local processes to global implications - a synthesis. Biogeosciences 5(5):1475-1491. https:// doi.org/10.5194/bg-5-1475-2008

Limpens J, Holmgren M, Jacobs CM, Van der Zee SE, Karofeld E, Berendse F (2014) How does tree density affect water loss of peatlands? Mesocosm Exp Plos One 9(3):e91748. https://doi. org/10.1371/journal.pone.0091748

Lindkvist L, Gustavsson T, Bogren J (2000) A frost assessment method for mountainous areas. Agric for Meteorol 102(1):51-67

Loisel J, Gallego-Sala AV, Amesbury MJ, Magnan G, Anshari G, Beilman DW, Benavides JC, Blewett J, Camill P, Charman DJ, Chawchai S, Hedgpeth A, Kleinen T, Korhola A, Large D, Mansilla CA, Müller J, van Bellen S, West JB, Yu Z, Bubier JL, Garneau M, Moore T, Sannel ABK, Page S, Väliranta M, Bechtold M, Brovkin V, Cole LES, Chanton JP, Christensen TR, Davies MA, De Vleeschouwer F, Finkelstein SA, Frolking S, Gałka M, Gandois L, Girkin N, Harris LI, Heinemeyer A, Hoyt AM, Jones MC, Joos F, Juutinen S, Kaiser K, Lacourse T, Lamentowicz M, Larmola T, Leifeld J, Lohila A, Milner AM, Minkkinen K, Moss P, Naafs BDA, Nichols J, O'Donnell J, Payne R, Philben M, Piilo S, Quillet A, Ratnayake AS, Roland TP, Sjögersten S, Sonnentag O, Swindles GT, Swinnen W, Talbot J, Treat C, Valach AC, Wu J (2021) Expert assessment of future vulnerability of the global peatland carbon sink. Nat Clim Chang 11(1):70-77. https://doi. org/10.1038/s41558-020-00944-0

Loranty MM, Abbott BW, Blok D, Douglas TA, Epstein HE, Forbes BC, Jones BM, Kholodov AL, Kropp H, Malhotra A, Mamet SD, Myers-Smith IH, Natali SM, O'Donnell JA, Phoenix GK, Rocha AV, Sonnentag O, Tape KD, Walker DA (2018) Reviews and syntheses: changing ecosystem influences on soil thermal regimes in northern high-latitude permafrost regions. Biogeosciences 15(17):5287-5313. https://doi.org/10.5194/ bg-15-5287-2018

Lundquist JD, Pepin N, Rochford C (2008). Automated algorithm for mapping regions of cold-air pooling in complex terrain. J Geophys Res 113(D22)

Łuców D, Lamentowicz M, Obremska M, Arkhipova M, Kittel P, Łokas E, Mazurkevich A, Mróz T, Tjallingii R, Słowiński M (2020) Disturbance and resilience of a Sphagnum peatland in western Russia (Western Dvina Lakeland) during the last 300 years: a multiproxy, high-resolution study. Holocene 30(11):1552-1566. https://doi.org/10.1177/0959683620941064

McLaughlin BC, Ackerly DD, Klos PZ, Natali J, Dawson TE, Thompson SE (2017) Hydrologic refugia, plants, and climate change. Glob Change Biol 23(8):2941-2961

Malhi Y, Franklin J, Seddon N, Solan M, Turner MG, Field CB, Knowlton N (2020) Climate change and ecosystems: threats, opportunities and solutions. Philos Trans R Soc Lond B Biol Sci 375(1794):20190104. https://doi.org/10.1098/rstb.2019. 0104

Malhotra A, Roulet NT, Wilson P, Giroux-Bougard X, Harris L (2016) Ecohydrological feedbacks in peatlands: an empirical test of the relationship among vegetation, microtopography and water table. Ecohydrology:n/a-n/a. https://doi.org/10.1002/ eco. 1731
Manoli G, Fatichi S, Bou-Zeid E, Katul GG (2020) Seasonal hysteresis of surface urban heat islands. Proc Natl Acad Sci U S A 117(13):7082-7089. https://doi.org/10.1073/pnas. 1917554117

Marcisz K, Tinner W, Colombaroli D et al (2015) Long-term hydrological dynamics and fire history over the last 2000 years in CE Europe reconstructed from a high-resolution peat archive. Quatern Sci Rev 112:138-152

Marcisz K, Jassey VEJ, Kosakyan A, Krashevska V, Lahr DJG, Lara E, Lamentowicz Ł, Lamentowicz M, Macumber A, Mazei Y, Mitchell EAD, Nasser NA, Patterson RT, Roe HM, Singer D, Tsyganov AN, Fournier B (2020) Testate amoeba functional traits and their use in paleoecology. Front EcolEvol 8. https:// doi.org/10.3389/fevo.2020.575966

Marcisz K, Lamentowicz L, Słowińska S, Słowiński M, Muszak W, Lamentowicz M (2014) Seasonal changes in Sphagnum peatland testate amoeba communities along a hydrological gradient. Eur J Protistol 50(5):445-455. https://doi.org/10.1016/j.ejop.2014. 07.001

Matuszkiewicz W (2001) A guide for the identification of Polish plant communities. Wydawnictwo Naukowe PWN, Warsaw: (in Polish)

Mitchell EAD, Charman DJ, Warner BG (2007a) Testate amoebae analysis in ecological and paleoecological studies of wetlands: past, present and future. Biodivers Conserv 17(9):2115-2137. https://doi.org/10.1007/s10531-007-9221-3

Mitchell EAD, Payne RJ, Lamentowicz M (2007b) Potential implications of differential preservation of testate amoeba shells for paleoenvironmental reconstruction in peatlands. J Paleolimnol 40(2):603-618. https://doi.org/10.1007/ s10933-007-9185-z

Moore TR, Bubier JL, Frolking SE, Lafleur PM, Roulet NT (2002) Plant biomass and production and $\mathrm{CO}_{2}$ exchange in an ombrotrophic bog. J Ecol 90(1):25-36. https://doi.org/10.1046/j.00220477.2001.00633.x

Moore TT (2011) Climate change and animal migration. Environ Law 41(2):393-405

Morelli TL, Daly C, Dobrowski SZ, Dulen DM, Ebersole JL, Jackson ST, Lundquist JD, Millar CI, Maher SP, Monahan WB, Nydick KR, Redmond KT, Sawyer SC, Stock S, Beissinger SR (2016) Managing climate change refugia for climate adaptation. PLoS ONE 11(8):e0159909. https://doi.org/10.1371/journal.pone. 0159909

Morris PJ, Waddington JM, Benscoter BW, Turetsky MR (2011) Conceptual frameworks in peatland ecohydrology: looking beyond the two-layered (acrotelm-catotelm) model. Ecohydrology 4(1):1-11. https://doi.org/10.1002/eco.191

Nichols JE, Peteet DM (2019) Rapid expansion of northern peatlands and doubled estimate of carbon storage. Nat Geosci. https://doi. org/10.1038/s41561-019-0454-Z

Noryśkiewicz AM (2005) Preliminary results of study on vegetation history in the Linje Mire region using pollen analysis. Postglacial vegetation changes in the development of raised mires in Poland, vol 94. POLISH BOTANICAL SOCIETY, Łódź

Oke TR (1987) Boundary Layer Climates. Routledge

Page SE, Baird AJ (2016) Peatlands and global change: response and resilience. Annu Rev Environ Resour 41(1):35-57. https://doi. org/10.1146/annurev-environ-110615-085520

Pappas C, Peters RL, Fonti P (2020) Linking variability of tree water use and growth with species resilience to environmental changes. Ecography. https://doi.org/10.1111/ecog.04968

Petrone RM, Price JS, Waddington JM, von Waldow H (2004) Surface moisture and energy exchange from a restored peatland, Québec. Canada J Hydrol 295(1-4):198-210. https://doi.org/10.1016/j. jhydrol.2004.03.009 
Peus F (1932) Die Tierwelt der Moore. Bornträger Verlag, Berlin, Handbuch der Moorkunde III (in German)

Price JS (1996) Hydrology and microclimate of a partly restored cutover bog. Quebec Hydrol Proc 10(10):1263-1272

R Core Team (2020) R: A language and environment for statistical computing. R Foundation for Statistical Computing, Vienna, Austria, URL https://www.R-project.org/

Reczuga MK, Seppey CVW, Mulot M, Jassey VEJ, Buttler A, Słowińska S, Słowiński M, Lara E, Lamentowicz M, Mitchell EAD (2020) Assessing the responses of Sphagnum micro-eukaryotes to climate changes using high throughput sequencing. PeerJ 8. https://doi.org/10.7717/peerj. 9821

Robroek BJM, Wubs ERJ, Marti M, Zajac K, Andersen JP, Andersson A, Borjesson G, Bragazza L, Dise NB, Keuskamp JA, Larsson M, Lindgren PE, Mattiasson P, Solomonsson J, Sundberg C, Syensson BH, Verhoeyen JTA (2014) Microclimatological consequences for plant and microbial composition in Sphagnumdominated peatlands. Boreal Environ Res 19(3):195-208

Romanov VV (1968) Hydrophysics of bogs. Israel Program for Scientific Translations. Jerusalem

Rull V (2009) Microrefugia. J Biogeogr 36(3):481-484. https://doi.org/ 10.1111/j.1365-2699.2008.02023.x

Rydin H, Jeglum JK (2013) The biology of peatlands.

Samson M, Słowińska S, Słowiński M, Lamentowicz M, Barabach J, Harenda K, Zielińska M, Robroek BJM, Jassey VEJ, Buttler A, Chojnicki BH (2018) The impact of experimental temperature and water level manipulation on carbon dioxide release in a poor fen in Northern Poland. Wetlands 3:551-563. https://doi.org/10. 1007/s13157-018-0999-4

Seddon AWR, Mackay AW, Baker AG, Birks HJB, Breman E, Buck CE, Ellis EC, Froyd CA, Gill JL, Gillson L, Johnson EA, Jones VJ, Juggins S, Macias-Fauria M, Mills K, Morris JL, NoguésBravo D, Punyasena SW, Roland TP, Tanentzap AJ, Willis KJ, Aberhan M, van Asperen EN, Austin WEN, Battarbee RW, Bhagwat S, Belanger CL, Bennett KD, Birks HH, Bronk Ramsey C, Brooks SJ, de Bruyn M, Butler PG, Chambers FM, Clarke SJ, Davies AL, Dearing JA, Ezard THG, Feurdean A, Flower RJ, Gell P, Hausmann S, Hogan EJ, Hopkins MJ, Jeffers ES, Korhola AA, Marchant R, Kiefer T, Lamentowicz M, Larocque-Tobler I, López-Merino L, Liow LH, McGowan S, Miller JH, Montoya E, Morton O, Nogué S, Onoufriou C, Boush LP, Rodriguez-Sanchez F, Rose NL, Sayer CD, Shaw HE, Payne R, Simpson G, Sohar K, Whitehouse NJ, Williams JW, Witkowski A, McGlone M (2014) Looking forward through the past: identification of 50 priority research questions in palaeoecology. J Ecol 102(1):256-267. https://doi.org/10.1111/1365-2745.12195

Settele J, Scholes R, Betts R, Bunn S, Leadley P, Nepstad D, Overpeck JT, Taboada MA (2014) Terrestrial and inland water systems. . Climate Change 2014: Impacts, Adaptation, and Vulnerability. Part A: Global and Sectoral Aspects. Contribution of Working Group II to the Fifth Assessment Report of the Intergovernmental Panel on Climate Change. Cambridge University Press, Cambridge, United Kingdom and New York, NY, USA

Shur YL, Jorgenson MT (2007) Patterns of permafrost formation and degradation in relation to climate and ecosystems. Permafr Periglac 18:7-19

Słowińska S (2016) Microclimate conditioning of small bogs and their surroundings functioning. Dissertation, Institute of Geography and Spatial Organization, Polish Academy of Sciences, Warsaw, Poland

Słowińska S, Słowiński M, Lamentowicz M (2010) Relationships between local climate and hydrology in Sphagnum mire implications for palaeohydrological studies and ecosystem management. Polish J of Environ Stud 19(4):779-787
Stanley CH, Helletsgruber C, Hof A (2019) Mutual influences of urban microclimate and urban trees: an investigation of phenology and cooling capacity. Forests 10 (7). https://doi.org/10.3390/f1007 0533

Steffen W, Rockström J, Richardson K, Lenton TM, Folke C, Liverman D, Summerhayes CP, Barnosky AD, Cornell SE, Crucifix M, Donges JF, Fetzer I, Lade SJ, Scheffer M, Winkelmann R, Schellnhuber HJ (2018) Trajectories of the Earth system in the anthropocene. Proc Natl Acad Sci. https://doi.org/10.1073/pnas. 1810141115

Stralberg D, Arseneault D, Baltzer JL, Barber QE, Bayne EM, Boulanger Y, Brown CD, Cooke HA, Devito K, Edwards J, Estevo CA, Flynn N, Frelich LE, Hogg EH, Johnston M, Logan T, Matsuoka SM, Moore P, Morelli TL, Morissette JL, Nelson EA, Nenzén H, Nielsen SE, Parisien MA, Pedlar JH, Price DT, Schmiegelow FKA, Slattery SM, Sonnentag O, Thompson DK, Whitman E (2020) Climate-change refugia in boreal North America: what, where, and for how long? Front Ecol Environ 18(5):261-270. https://doi.org/10.1002/fee.2188

Succow M (1988) Landschaftsökologische Moorkunde. Jena

Swindles GT, Morris PJ, Mullan DJ, Payne RJ, Roland TP, Amesbury MJ, Lamentowicz M, Turner TE, Gallego-Sala A, Sim T, Barr ID, Blaauw M, Blundell A, Chambers FM, Charman DJ, Feurdean A, Galloway JM, Gałka M, Green SM, Kajukało K, Karofeld E, Korhola A, Lamentowicz Ł, Langdon P, Marcisz K, Mauquoy D, Mazei YA, McKeown MM, Mitchell EAD, Novenko E, Plunkett G, Roe HM, Schoning K, Sillasoo Ü, Tsyganov AN, van der Linden M, Väliranta M, Warner B (2019) Widespread drying of European peatlands in recent centuries. Nat Geosci 12(11):922-928. https://doi.org/10.1038/s41561-019-0462-z

Szwed M, Karg G, Pińskwar I, Radziejewski M, Graczyk D, Kedziora A, Kundzewicz ZW (2010) Climate change and its effect on agriculture, water resources and human health sectors in Poland. Nat Hazards Earth Syst Sci 10:1725-1737

Tobolski K (2000) Przewodnik do oznaczania torfów i osadów jeziornych Vademecum Geobotanicum (in Polish)

Turetsky MR, Donahue WF, Benscoter BW (2011) Experimental drying intensifies burning and carbon losses in a northern peatland. Nat Commun 2:514. https://doi.org/10.1038/ncomm s1523

von Arx G, Dobbertin M, Rebetez M (2012) Spatio-temporal effects of forest canopy on understory microclimate in a long-term experiment in Switzerland. Agric for Meteorol 166-167:144-155. https://doi.org/10.1016/j.agrformet.2012.07.018

Waddington JM, Morris PJ, Kettridge N, Granath G, Thompson DK, Moore PA (2015) Hydrological feedbacks in northern peatlands. Ecohydrology 8(1):113-127

Wasof S, Lenoir J, Gallet-Moron E, Jamoneau A, Brunet J, Cousins SAO, De Frenne P, Diekmann M, Hermy M, Kolb A, Liira J, Verheyen K, Wulf M, Decocq G (2013) Ecological niche shifts of understorey plants along a latitudinal gradient of temperate forests in north-western Europe. Glob Ecol Biogeogr 22(10):11301140. https://doi.org/10.1111/geb.12073

Wheeler BD, Proctor MCF (2000) Ecological gradients, subdivisions and terminology of north-west European mires. J Ecol 88(2):187-203. https://doi.org/10.1046/j.1365-2745.2000. 00455. $\mathrm{x}$

Wickham H (2016) ggplot2: elegant graphics for data analysis.

Wieder RK, Vitt DH (2006) Boreal peatland ecosystems. Springer

Winter TC (2000) The vulnerability of wetlands to climate change: a hydrologic landscape perspective. JAWRA J Am Water Resour Assoc 36(2):305-311. https://doi.org/10.1111/j.1752-1688.2000. tb04269.x

WMO (2018) Measurement of meteorological variables. Guide to Instruments and Methods of Observation, vol 1. 
Worrall F, Boothroyd IM, Gardner RL, Howden NJK, Burt TP, Smith R, Mitchell L, Kohler T, Gregg R (2019) The impact of peatland restoration on local climate - restoration of a cool humid island. Journal of Geophysical Research: Biogeosciences. https://doi. org/10.1029/2019jg005156

Yu Z, Beilman DW, Frolking S, MacDonald GM, Roulet NT, Camill P, Charman DJ (2011) Peatlands and their role in the global carbon cycle. EOS Trans Am Geophys Union 92(12):97-98. https://doi. org/10.1029/2011eo120001

Zarzycki K, Mirek Z (2006) Red list of plants and fungi in Poland. Instytut Botaniki im. W. Szafera PAN, Kraków: (in Polish)
Zellweger F, Coomes D, Lenoir J, Depauw L, Maes SL, Wulf M, Kirby KJ, Brunet J, Kopecky M, Malis F, Schmidt W, Heinrichs S, den Ouden J, Jaroszewicz B, Buyse G, Spicher F, Verheyen K, De Frenne P (2019) Seasonal drivers of understorey temperature buffering in temperate deciduous forests across Europe. Glob Ecol Biogeogr 28(12):1774-1786. https://doi.org/10.1111/geb. 12991

Zhao L, Lee X, Smith RB, Oleson K (2014) Strong contributions of local background climate to urban heat islands. Nature 511(7508):216-219 